\title{
PARADIPLOMACIA COMO FERRAMENTA PARA DESENVOLVIMENTO DAS CIDADES-GÊMEAS DA FRONTEIRA BRASILEIRA
}

Deise Baumgratz ${ }^{1}$

RESUMO: O artigo a seguir analisa as condições de desenvolvimento das cidades de fronteiras, numa perspectiva comparativa à média nacional de indicadores como mortalidade infantil, renda, educação, esgotamento sanitário e IDH. A hipótese apresentada é de que as cidades fronteiriças apresentam indicadores inferiores à média nacional. Na sequência é discutido as teorias recentes sobre paradiplomacia, indicando as possibilidades de utilizar destes mecanismos para melhorar o desenvolvimento sustentável e a cooperação transnacional nas cidades de fronteira. Por fim, apresenta-se dois estudos de caso de cidades fronteiriças que se utilizam da paradiplomacia para promover a integração e o desenvolvimento regional. A metodologia utilizada envolve análise de dados secundários, essencialmente do IBGE, análise bibliográfica e estudo de caso. Os resultados apontam para a paradiplomacia como alternativa para promover o desenvolvimento e a cooperação transfronteiriça.

Palavras-chave: Paradiplomacia; Cooperação Transfronteiriça; Fronteira.

\section{PARADIPLOMACY AS A TOOL FOR THE DEVELOPMENT OF TWIN CITIES ON THE BRAZILIAN FRONTIER}

\begin{abstract}
The following article analyzes the development conditions of border cities, in a perspective comparative to the national average of indicators such as infant mortality, income, education, sanitation and HDI. The hypothesis presented is that border cities have indicators below the national average. Following, the recent theories on paradiplomacy are discussed, indicating the possibilities of using these mechanisms to improve sustainable development and transnational cooperation in border cities. Finally, two case studies of border cities that use the paradiplomacy to promote regional integration and development are presented. The methodology used involves analysis of secondary data, essentially from IBGE, bibliographic analysis and case study. The results point to paradiplomacy as an alternative to promote development and cross-border cooperation.
\end{abstract}

Keywords: Paradiplomacy; Cross-border cooperation; Border.

\section{INTRODUÇÃO}

\footnotetext{
${ }^{1}$ Doutoranda do programa de pós-graduação em Desenvolvimento Regional da Universidade Federal Tecnologica do Paraná, mestre em Sociedade, Cultura e Fronteiras pela Universidade Estadual do Oeste do Paraná, especialista em Relações Internacionais e graduada em administração. baumgratz9@ gmail.com

2 Mestrando do Programa de Pós-graduação em Relações Internacionais - Universidade Federal da Integração Latino-Americana. gherlandi@gmail.com
} 
$\mathrm{O}$ artigo a seguir analisa o panorama das cidades fronteiriças brasileiras, visando identificar possibilidades de atuação da paradiplomacia no desenvolvimento dessas localidades. Desse modo, o objetivo do estudo é identificar em que âmbitos a atuação paradiplomática transfronteiriça no Brasil logrou resultados concretos e se esses resultados contribuíram para um aumento do desenvolvimento nessas regiões. A hipótese é de que a paradiplomacia facilita processos de cooperação transfronteiriça contribuindo para o desenvolvimento de regiões transfronteiriças.

Nesses termos, inicia-se o estudo comparando indicadores de educação, renda, mortalidade, saneamento entre outros, das cidades de fronteira no Brasil, com a média nacional, a fim de demonstrar que os municípios de fronteira apresentam indicadores inferiores à média nacional. A pesquisa demonstrou que a razão para a marginalidade das regiões fronteiriças no processo de desenvolvimento nacional, se insere no contexto histórico, onde fronteira foi considerada limite divisório entre dois Estados, portanto, foi protegida e securitizada, concebida como espaço de segurança nacional e periférica nos processos decisórios e nas políticas públicas centrais.

Houve uma mudança de perspectiva com a ascensão global das discussões em torno da integração regional, dentro das Relações Internacionais a paz positiva passou a ser almejada, mudando a visão realista conflitiva para uma abertura cooperativa e de integração. Nesse contexto surge em 1991 o Mercosul e, principalmente a partir dos anos 2000, com uma guinada à esquerda vivenciada na América Latina, houve o fortalecimento do bloco e uma tentativa de inclusão das fronteiras no processo de desenvolvimento nacional, no caso do Brasil.

Destarte, na primeira seção serão discutidos os dados das fronteiras brasileiras, com fonte do IBGE, plataforma "cidades", comparando com os indicadores nacionais, representado na Tabela I e nos gráficos subsequentes. Ao longo da primeira seção, será realizado um breve apanhado referente às mudanças de políticas públicas para as regiões de fronteira.

Dando continuidade à pesquisa, a segunda seção tem como objetivo debater e apresentar o conceito de paradiplomacia defendido pelos autores, definido como: a interação de governos não-centrais - compreendidos aqui como o conjunto de entidades que extrapolam as estruturas formais do estado na formulação de políticas públicas, incluindo portanto não apenas o setor público, mas podendo também conter o setor 
privado, o terceiro setor e sociedade civil - com atores submetidos a jurisdições distintas da sua (provenientes de outro Estado ou economia) com o objetivo de promover questões diversas de forma a mediar realidades distintas convergentes ou não. Além disso, também é abordada a aplicabilidade da paradiplomacia em regiões de fronteira. Para tanto, será apresentado um debate entre conceitos a partir de revisão bibliográfica.

Por fim, apresentam-se os estudos de caso sobre o Consórcio Intermunicipal de Fronteira (CIF), conformado pelas cidades de Barracão - PR, Bom Jesus do Sul - PR, Dionísio Cerqueira - SC e extraoficialmente pelo município de Bernardo de Irigoyen/Missiones na Argentina; e o Conselho de Desenvolvimento Trinacional, composto por entidades das cidades de Foz do Iguaçu - BR, Ciudad del Este - PY, e Puerto Iguazu - AR, como exemplos de aplicação da paradiplomacia no desenvolvimento regional transfronteiriço. Observado, se, e como, a paradiplomacia pode ser conveniente para essas regiões. Os dados utilizados nesta seção são dos sites oficiais dos processos de cooperação, assim como de revisão bibliográfica sobre o assunto.

\section{FRONTEIRAS BRASILEIRAS, UM PANORAMA GERAL}

Conforme a Constituição Federal de 1988, constitui-se como fronteira o limite de $150 \mathrm{~km}$ da linha divisória de dois países. Neste contexto, o Brasil apresenta mais de 15 mil quilômetros de fronteira com 10 países, cerca de 30\% do território nacional está dentro do limite de fronteira (CDIF, 2012. p.6).

Historicamente a fronteira marca-se como um espaço estratégico para a segurança nacional e, portanto, é severamente protegido. Os governos investem na proteção de suas divisas, é frequente a presença do exército e de outras forças de Estado para demarcar a soberania e proteção do espaço nacional, conforme ilustrado pelo secretário de desenvolvimento Sérgio Castro em 2012 “à região da fronteira, historicamente não [é] tratada na perspectiva da aproximação e integração, mas a partir da concepção da defesa e do isolamento" (CDIF, 2012.p. 13).

Entretanto, após o fim da Guerra Fria, com a queda do muro de Berlim, também houve uma queda nos conceitos de separação e militarização das fronteiras, lentamente encaminhou-se um movimento global para a integração regional. Foi assim que, em 1991, surgiu o Mercado Comum do Sul (Mercosul). 
Em sua criação, o alinhamento do Mercosul foi essencialmente econômico, preservando as bases do neoliberalismo tão presente no contexto latino americano na década de 1990, através do Consenso de Washington. Contudo, o passar dos anos, transformaram o perfil de cooperação no Mercosul, para uma visão mais abrangente, envolvendo fluxo de mercadorias, pessoas, profissionais e inclusive a cooperação educacional. Essa mudança se acentua a partir dos anos 2000, quando concomitantemente, observa-se uma ascensão de governos de esquerda nos países membros, os quais convergem nos objetivos para o bloco, facilitando a integração em contextos mais amplos.

A marginalidade das fronteiras nacionais, no sentido de estar na margem geográfica e também política, coloca as regiões de fronteira em situação vulnerável. Nosso objetivo nesta seção é analisar os indicadores econômicos, de analfabetismo, mortalidade infantil, renda e saúde das cidades de fronteira em comparação com a média nacional. Para tanto, elencamos como limitação de pesquisa as cidades gêmeas, de acordo com a definição do Ministério da Integração na Portaria No - 125, DE 21 DE MARÇO DE $2014^{3}$.

\begin{tabular}{|l|l|l|l|l|l|l|l|l|}
\hline & $\begin{array}{l}\text { PIB per } \\
\text { capita } \\
\mathbf{2 0 1 7}\end{array}$ & $\begin{array}{l}\text { IDH } \\
\mathbf{2 0 1 0}\end{array}$ & $\begin{array}{l}\text { Morta } \\
\text { lidade } \\
\text { Infant } \\
\text { il } \\
\mathbf{2 0 1 7}\end{array}$ & $\begin{array}{l}\text { Escolari } \\
\text { zação (6 } \\
\text { a } \\
\text { anos) }\end{array}$ & $\begin{array}{l}\text { população } \\
\text { Estimada } \\
\text { em 2020 }\end{array}$ & $\begin{array}{l}\text { salári } \\
\text { o } \\
\text { médio } \\
\mathbf{2 0 1 8}\end{array}$ & $\begin{array}{l}\text { Rendimento } \\
\text { mensal de } \\
\text { até } 1 / 2 \text { salário } \\
\text { mínimo (\%) } \\
\mathbf{2 0 1 8}\end{array}$ & $\begin{array}{l}\text { Esgota } \\
\text { mento } \\
\text { sanitári } \\
\text { o } \\
\text { adequa } \\
\text { do } \\
\mathbf{2 0 1 0}\end{array}$ \\
\hline Nacional & $31.833,50$ & 0,726 & 12,35 & 99,7 & 211.755 .692 & 2,63 & 30 & 88,29 \\
\hline Bonfim & $22.359,75$ & 0,626 & 31,83 & 91,9 & 12.557 & 1,7 & 47,7 & 35,9 \\
\hline
\end{tabular}

\footnotetext{
${ }^{3}$ Serão considerados cidades-gêmeas os municípios cortados pela linha de fronteira, seja essa seca ou fluvial, articulada ou não por obra de infraestrutura, que apresentem grande potencial de integração econômica e cultural, podendo ou não apresentar uma conurbação ou semi-conurbação com uma localidade do país vizinho, assim como manifestações "condensadas" dos problemas característicos da fronteira, que aí adquirem maior densidade, com efeitos diretos sobre o desenvolvimento regional e a cidadania. Art. $2^{\circ}$ Não serão consideradas cidades-gêmeas aquelas que apresentem, individualmente, população inferior a 2.000 (dois mil) habitantes (BRASIL, 2014, p.45), disponível em: //pesquisa.in.gov.br/imprensa/jsp/visualiza/index.jsp?jornal=1\&pagina=45\&data=24/03/2014. Acesso em 08/10/2020

${ }^{4}$ Dado obtido pelo rendimento médio nacional em 2010 (1345) dividido pelo salário da época $\mathrm{R} \$ 510,00$ fonte:http://prattein.com.br/home/images/stories/Direitos_da_Criana_e_do_Adolescente/resultados_gerai s_amostra.pdf
} 
Revista eletrônica de Filosofia

Alamedas

\begin{tabular}{|c|c|c|c|c|c|c|c|c|}
\hline Pacaraima & $13.880,70$ & 0,650 & 39,47 & 93 & 18.913 & 1,8 & 46,5 & 21,4 \\
\hline Aceguá & $55.081,87$ & 0,687 & 20,41 & 93,9 & 4394 & 2,5 & 36,3 & 82,2 \\
\hline Barra do Quaraí & $47.852,46$ & 0,662 & 18,87 & 97,7 & 4227 & 1,9 & 41,3 & 66,3 \\
\hline Chuí & $37.264,87$ & 0,706 & 27,73 & 97,7 & 6770 & 1,8 & 35 & 83,4 \\
\hline Itaqui & $34.314,16$ & 0,713 & 18,15 & 98,7 & 37489 & 2,3 & 35,7 & 68,5 \\
\hline Jaguarão & $25.658,02$ & 0,707 & 24,62 & 97,1 & 26500 & 2,1 & 32,8 & 61,9 \\
\hline Porto Xavier & $14.556,10$ & 0,723 & 8,7 & 99,5 & 10.194 & 2,1 & 35 & 49,3 \\
\hline Quaraí & $18.918,34$ & 0,704 & 24,69 & 99,4 & 22607 & 1,8 & 34,6 & 85,7 \\
\hline $\begin{array}{ll}\text { Santana } & \text { do } \\
\text { Livramento } & \end{array}$ & $31.288,14$ & 0,727 & 15,47 & 97,6 & 76321 & 2,2 & 33,9 & 79,5 \\
\hline Sao Borja & $28.405,45$ & 0,736 & 10,94 & 97,5 & 60019 & 2,2 & 37 & 62,2 \\
\hline Uruguaiana & $21.633,17$ & 0,744 & 12,26 & 97,6 & 126.866 & 2,2 & 35,6 & 81,2 \\
\hline $\begin{array}{l}\text { Dionísio } \\
\text { Cerqueira }\end{array}$ & $25.916,36$ & 0,706 & 9,48 & 96,6 & 15.545 & 2,0 & 36,3 & 41,2 \\
\hline Porto Mauá & $21.436,67$ & 0,698 & 55,56 & 100 & 2352 & 2,5 & 37 & 54 \\
\hline Barracão & $22.298,89$ & 0,706 & 6,71 & 95,3 & 10312 & 1,9 & 34,2 & 52,9 \\
\hline $\begin{array}{l}\text { Santo Antônio } \\
\text { do Sudoeste }\end{array}$ & $25.160,40$ & 0,671 & 3,27 & 96,6 & 20.261 & 1,8 & 36,2 & 74,4 \\
\hline Foz do Iguaçu & $\begin{array}{l}50.9990,8 \\
9\end{array}$ & 0,751 & 12,04 & 96,4 & 258248 & 2,8 & 33,4 & 75,3 \\
\hline Guaíra & $26.591,39$ & 0,724 & 14,11 & 95,9 & 33310 & 2,2 & 33 & 51 \\
\hline Bela Vista & $21.192,63$ & 0,698 & 20,55 & 96 & 24735 & 2,1 & 40,6 & 22,7 \\
\hline Corumbá & $26.107,73$ & 0,700 & 17,48 & 94,7 & 112058 & 2,8 & 37,6 & 19,3 \\
\hline Mundo Novo & $25.597,35$ & 0,686 & 20,34 & 97 & 18473 & 2,1 & 32,3 & 1,1 \\
\hline Paranhos & 11.524 & 0,588 & 21,2 & 91,6 & 14404 & 2,2 & 46,6 & 1,4 \\
\hline Ponta Porã & $29.484,92$ & 0,701 & 11,72 & 96,9 & 93937 & 2,2 & 38,1 & 22,4 \\
\hline $\begin{array}{l}\text { Coronel } \\
\text { Sapucaia }\end{array}$ & $12.840,71$ & 0,589 & 18,29 & 84 & 15352 & 1,8 & 46 & 32,2 \\
\hline Porto Murtinho & $19.037,10$ & 0,666 & 7,84 & 94,1 & 17298 & 2,5 & 40,4 & 84,4 \\
\hline Assis Brasil & $13.132,06$ & 0,588 & 8,03 & 85,1 & 7534 & 2,2 & 47,1 & 23,1 \\
\hline Brasiléia & $15.663,67$ & 0,614 & 17,54 & 90,2 & 26702 & 1,8 & 45 & 28,4 \\
\hline
\end{tabular}




\begin{tabular}{|l|l|l|l|l|l|l|l|l|}
\hline Epitaciolândia & $25.139,04$ & 0,653 & 10,31 & 93,7 & 18696 & 1,6 & 42,9 & 21,4 \\
\hline $\begin{array}{l}\text { Santa Rosa do } \\
\text { Purus }\end{array}$ & $11.439,99$ & 0,517 & 25,25 & 63,8 & 6717 & 2,1 & 48,3 & 2,5 \\
\hline Cácere & $19.896,86$ & 0,708 & 16,59 & 97,8 & 94861 & 3,3 & 37,7 & 59,6 \\
\hline Oiapoque & $15.462,09$ & 0,658 & 25,13 & 96 & 27906 & 1,8 & 42,5 & 24,8 \\
\hline Guajará-Mirim & $16.955,80$ & 0,657 & 21,38 & 93,1 & 46556 & 2,0 & 41,4 & 20,5 \\
\hline Tabatinga & $7.255,96$ & 0,616 & 22,93 & 91,2 & 67182 & 2,0 & 48,2 & 21,6 \\
\hline
\end{tabular}

Fitando os dados disponíveis, identificamos variação expressiva entre as cidades de fronteira em comparação com a média nacional, quando observamos o salário médio, com exceção de Foz do Iguaçu, Cáceres e Corumbá, as demais cidades estão abaixo da média nacional, conforme gráfico 1.

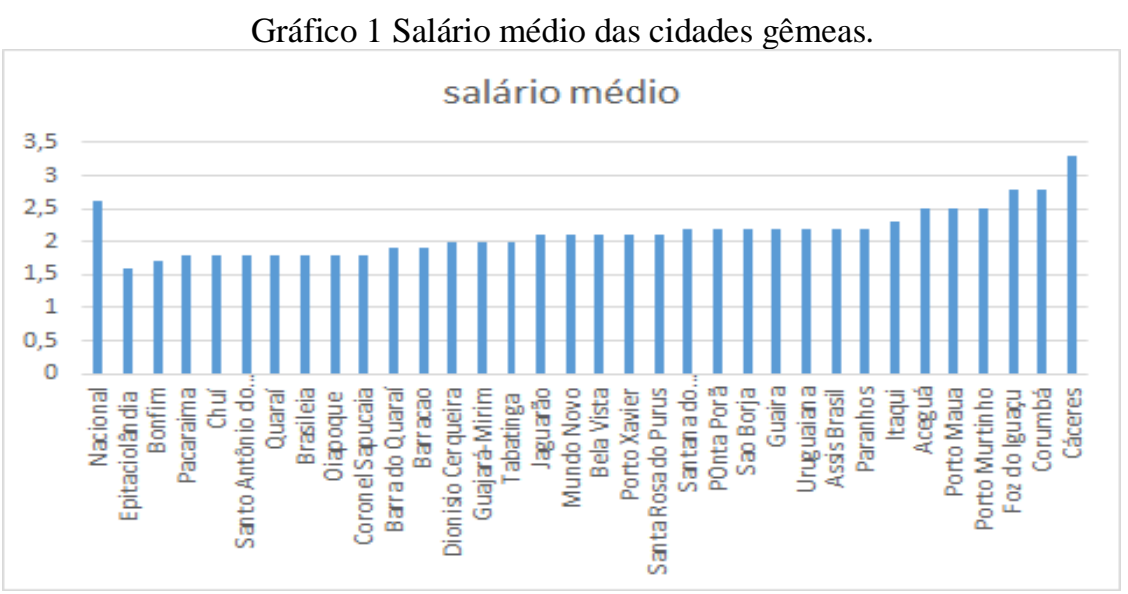

Fonte: Elaboração própria com dados IBGE, 2020.

Entretanto, cabe salientar que este dado por si pode ser um indicador falho, uma vez que a distribuição de renda frequentemente é desigual. Em função disso, trazemos luz ao indicador referente a porcentagem de pessoas que vivem com até meio salário mínimo, neste item todas as cidades gêmeas ficaram acima da média nacional, ou seja, uma grande parcela da população vive em situação de vulnerabilidade, conforme gráfico 2.

Gráfico 2 Porcentagem da população que vive com até meio salário mínimo em 2010. 


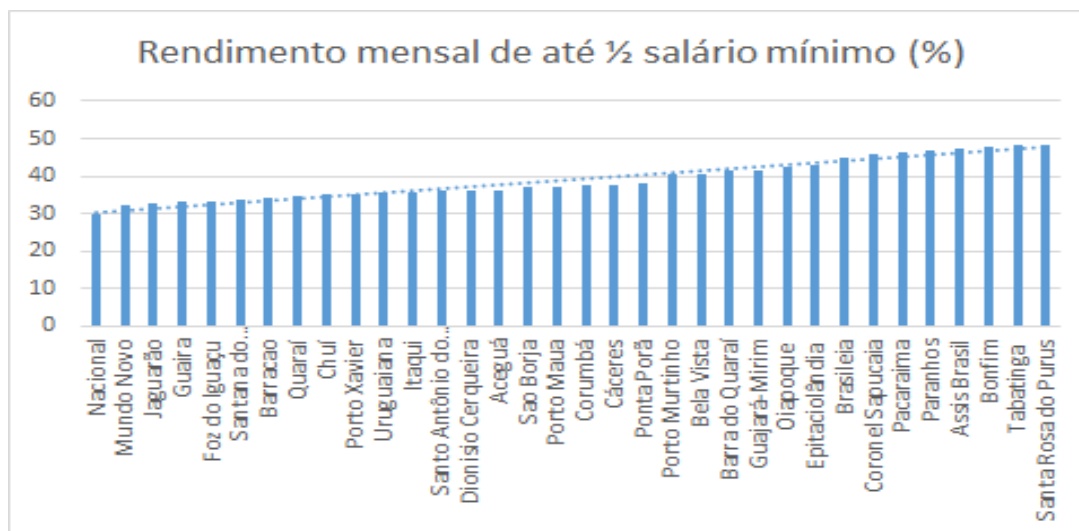

Fonte: Elaboração própria com dados IBGE, 2020.

No tangente a desenvolvimento, um conceito importante de considerar é o de Amartya Sen (2000), ele realiza uma análise crítica do desenvolvimento econômico, alertando para o aumento das desigualdades originados no processo. Do mesmo modo, aponta que desenvolvimento deveria ser o processo de ampliação das liberdades constitutivas dos indivíduos, tais como acesso a saúde, educação, alimentação digna e emprego.

De modo geral, o desenvolvimento amplo, como descrito por Sen (2000), é limitado nos países periféricos, o caso do Brasil está incluído nesta situação, entretanto, quando observamos os dados das cidades de fronteira, é possível notar um processo de desenvolvimento aquém do obtido a nível nacional. Ao focar em alguns fatores essa diferença é alarmante, que é o caso do indicador de esgotamento sanitário adequado, todas as cidades estão abaixo da média nacional, e alguns municípios apresentam valores próximo a zero, vejamos o gráfico 3. Ressaltamos a diferença conforme a região, o arco sul possui valores melhores se comparados ao eixo central e norte do país.

Gráfico 3 Porcentagem da população com esgotamento sanitário adequado 2010. 

Filosofia

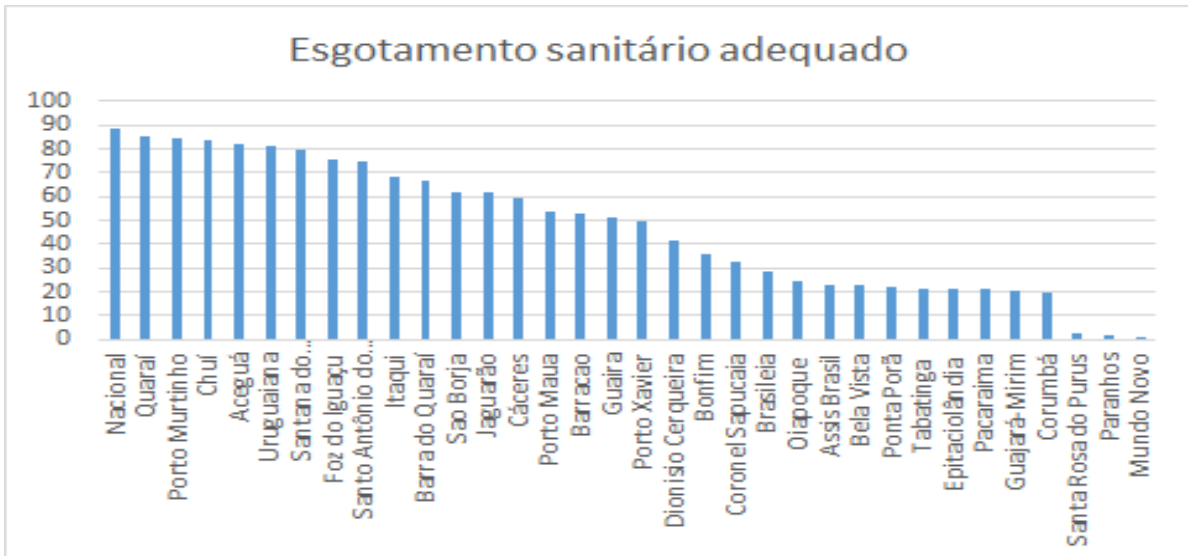

Fonte: Elaboração própria com dados IBGE, 2020.

No âmbito educacional, apenas a cidade de Porto Mauá, possui indicador de $100 \%$ de escolarização na idade de 06 a 14 anos, os outros municípios apresentam valores inferiores à média nacional, ainda que próximos. Assis Brasil $(85,1 \%)$, Coronel Sapucaia (84\%) e Santa Rosa do Purus (63,8\%) são os piores índices entre os dados analisados.

Gráfico 4 Porcentagem de escolarização na idade de 6 a 14 anos.

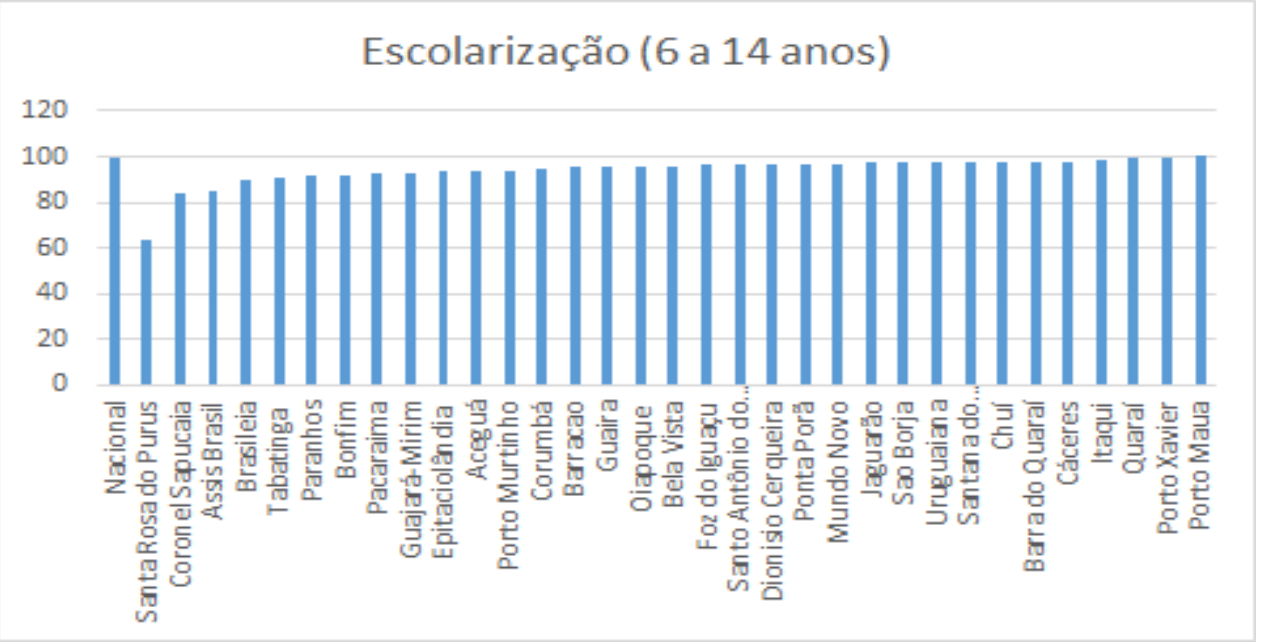

Fonte: Elaboração própria com dados IBGE, 2020.

O índice de mortalidade infantil chama atenção, apesar de haver 11 municípios abaixo do nível nacional, outros 20 municípios estão acima e alguns com números bem elevados, como Porto Mauá, com 55,56 mortes por 1000 nascidos vivos, um contraste com o indicador de educação, onde a cidade atingiu 100\% de escolarização. 


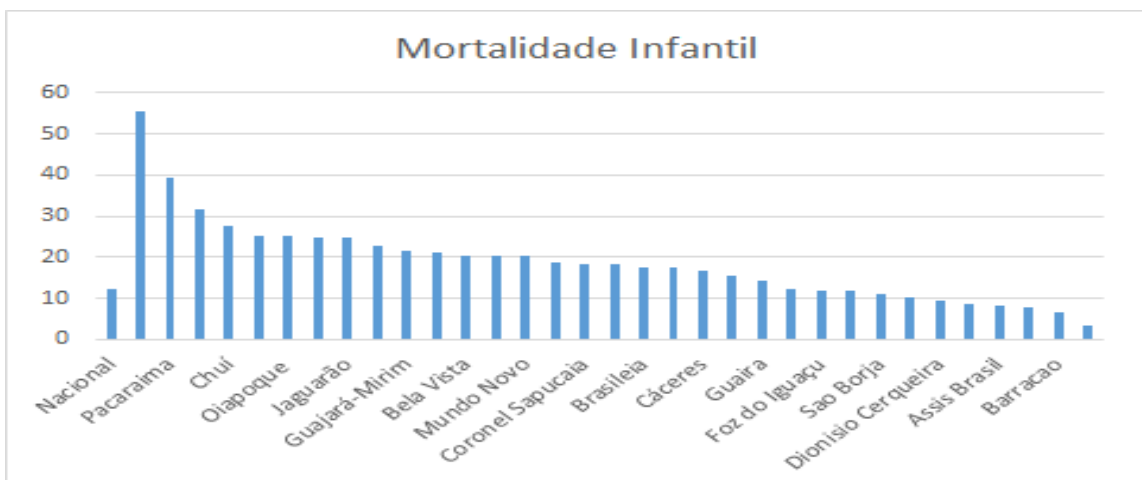

Gráfico 5 Mortalidade infantil a cada 1000 nascidos vivos. Fonte: elaboração própria, com dados IBGE, 2020.

O Índice de Desenvolvimento Humano - IDH, como reflexo dos outros dados já citados é menor à média nacional na maioria dos municípios pesquisados, Foz do Iguaçu, Uruguaiana, São Borja e Santana do Livramento estão acima da média. Destaca-se quatro municípios com IDH baixo (menor que 600), Coronel Sapucaia, Paranhos, Assis Brasil e Santa Rosa do Purus.

Gráfico 6 IDH das cidades gêmeas.

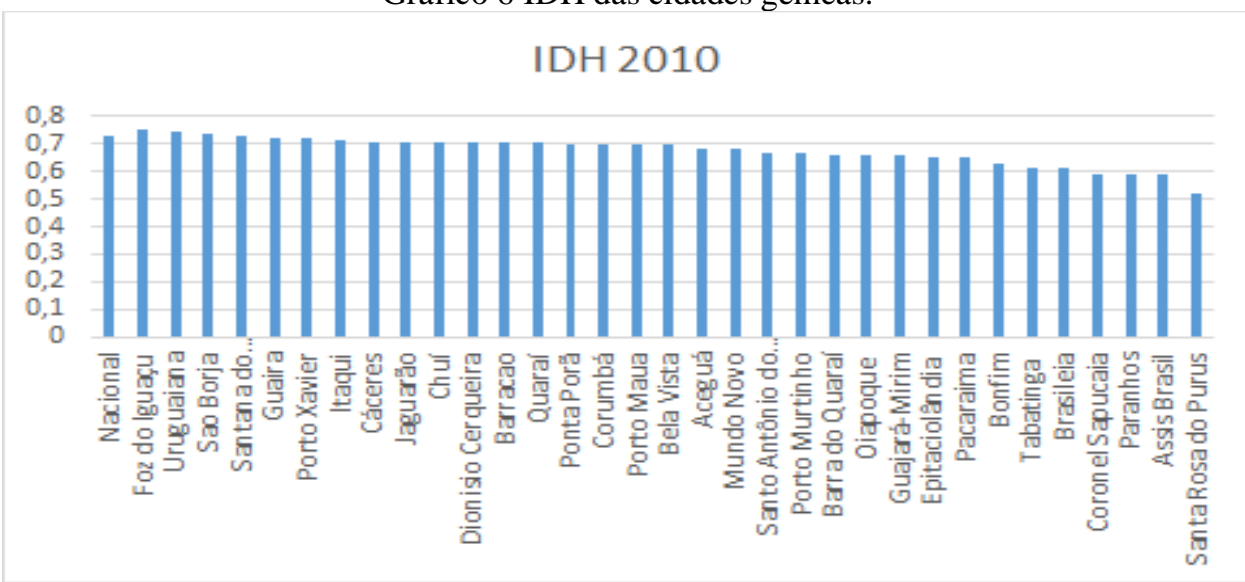

Fonte: elaboração própria, com dados IBGE, 2020.

Até aqui identificamos o cenário das cidades gêmeas por meio dos dados socioeconômicos, evidenciamos que, apesar de algumas cidades possuírem IDH ligeiramente superior à média nacional, a maioria dos municípios se encontra abaixo da média. Sobressai o fato de alguns lugares possuírem péssimas condições de saneamento, assim como uma percentagem elevada de pessoas viverem com menos de meio salário mínimo nestas cidades. Isso indica que o processo de desenvolvimento das regiões de fronteira serem deficitários se comparadas no nível nacional. 
Os dados apresentados, confirmam a hipótese levantada no início desta seção, de que as fronteiras ocupam uma posição marginal, tanto geograficamente, como politicamente e no processo de desenvolvimento. As decisões e leis são formuladas a nível central, considerando uma pretensa homogeneidade entre as regiões e aplicadas a todos os estados, sem considerar as particularidades de cada espaço.

Contudo, durante o governo petista no Brasil, houve um espaço de aproximação e de visibilização das fronteiras, o então Ministério da Integração, junto com o MEC, solicitaram estudos ao Grupo Retis da Universidade Federal do Rio de Janeiro (UFRJ), sobre o panorama de fronteiras. Neste período houve uma série de políticas voltadas para o desenvolvimento da faixa de fronteira, através de órgãos criados como o Programa de desenvolvimento Social da Faixa de Fronteira (PDFF) organizado pela Comissão permanente para o Desenvolvimento e a Integração da Faixa de Fronteira (CDIF).

Camilo Pereira Carneiro Filho e Lisa Belmiro Camara (2019), realizam um estudo com o mapeamento das "Políticas públicas na faixa de fronteira do Brasil: PDFF, CDIF e as políticas de segurança e defesa", onde elencam as diferentes estratégias para promover o desenvolvimento destas regiões periféricas. Essa estratégia faz parte, como mencionado brevemente na introdução a essa seção, de uma política de Estado que vislumbrava o fortalecimento da integração regional e de organismos interestatais e supranacionais como o Mercosul, a partir da interação direta do governo central nas regiões fronteiriças. Entretanto, conforme indicado pelos dados acima, as ações não foram suficientes para promover o desenvolvimento sustentável das fronteiras.

Frente a isso, a hipótese que apresentamos neste estudo, é que outra forma de promover o desenvolvimento destas regiões seja através da paradiplomacia, conceito a ser trabalhado na próxima seção. Deste modo, para finalizar iremos lançar luz à algumas práticas de paradiplomacia em municípios específicos para demonstrar como a cooperação transfronteiriça e a paradiplomacia podem contribuir para o desenvolvimento regional fronteiriço.

\section{PARADIPLOMACIA E FRONTEIRAS}

A discussão a respeito da paradiplomacia aparece na academia das relações internacionais durante a década de 1980 a partir das contribuições de Ivo Duchacek e 
Panayotis Soldatos. Segundo Aguirre (1999), esses autores, atentos ao aumento do envolvimento de governos não-centrais (GNC), principalmente estados federativos, passam a conceitualizar a inserção internacional desses atores verificando suas relações com a atuação dos governos centrais.

Nesse momento, o conceito de paradiplomacia, ainda em fase de formulação, conjuntamente com outros conceitos similares, tais como protodiplomacia e microdiplomacia, aparecia atrelado à projeção de regiões transfronteiriças que, por serem geograficamente contíguas, passaram a interagir de forma conjunta e intencional no plano internacional a fim de se fortalecerem (Aguirre, 1999). Nesse sentido, é importante destacar que o conceito, facilmente associado a uma ideia de diplomacia paralela a um único Estado, podendo ainda ser interpretado como uma diplomacia acessória a diplomacia central, surge mais atrelado às intenções de cooperativismo transfronteiriço não-institucionalizado, do que como projeção de atores sub-nacionais ou sub-estatais individualmente.

Além dessas constatações, é importante dizer que o conceito vai sendo delineado de forma a oferecer uma alternativa a ideia de protodiplomacia também desenvolvida por Duchacek e Soldatos (1990 apud. Aguirre, 1999) a qual se referiria ao posicionamento de regiões subnacionais, podendo ser transfronteiriças ou não, almejando estabelecer-se como região soberana. Dessa forma, a paradiplomacia, ao contrário, representaria para esses autores o contato direto de governos não-centrais com suas contrapartes também não-centrais nas mais diversas áreas a fim de, assim como na diplomacia "formal", estabelecer negociações e implementar acordos mútuos.

Ainda nessa época, década de 1980, outro autor que se dedicou ao tema foi James Der Derian (1987). O teórico desenvolve sua análise a respeito das práticas paradiplomáticas por meio da compreensão histórica do que a diplomacia (central, formal) representou desde o início das Relações Internacionais: um processo de mediação de unidades-estatais afastadas por um contexto internacional hobbesiano ${ }^{5}$ (AGUIRRE, 1999).

\footnotetext{
${ }^{5}$ Perspectiva tradicional das teorias Realistas de Relações Internacionais que argumentava que os Estados interagiam em um sistema anárquico composto por atores soberanos (os Estados) em um estado de guerra de todos contra todos.
} 
A partir disso, compreendendo a atividade diplomática como uma mediação entre realidades mutuamente estranhas em alguma medida, para o autor a paradiplomacia poderia significar "qualquer tipo de atividade internacional não governamental de atores não-estatais [...] que poderiam ser amplamente rotulados de "diplomáticos" porque realmente operam, [...], uma "mediação" entre realidades mutuamente "estranhas" ou "alienadas". (AGUIRRE, 1999, p.196-197). Para Der Derian, (apud. AGUIRRE, 1999 a etimologia do conceito revela a prática paradiplomática como uma atividade lateral à diplomacia do governo central, “é uma 'diplomacia' politicamente 'excêntrica', democraticamente não controlada, privada ou corporativa, religiosa ou mediática, estritamente não governamental" (AGUIRRE, 1999, p. 195)

Em contraposição, Noé Conargo (1999), propõe uma definição mais restritiva quanto ao ator preponderante da atuação paradiplomática. Para o autor a paradiplomacia se refere diretamente ao envolvimento de governos não centrais nas relações internacionais:

A paradiplomacia pode ser definida como o envolvimento de governos não centrais nas relações internacionais por meio do estabelecimento de contatos permanentes ou ad hoc com entidades estrangeiras, públicos ou privados, com o objetivo de promover questões socioeconômicas ou culturais, bem como qualquer outra dimensão estrangeira das suas competências constitucionais. (CONARGO, 1999 In KEATING; ALDECOA, 1999, tradução nossa).

Desse modo, observa-se que, embora o conceito de Conargo seja amplamente utilizado, não há consenso sobre a participação governamental ser determinante para caracterizar a atuação paradiplomática. Contudo, verifica-se na literatura sobre o tema a existência de autores que defendem uma visão ampliada de governo, o que pode solucionar essa questão.

Michael Keating (2001) compreende o conceito de governo como algo a "mais do que as estruturas formais do Estado" (KEATING, 2001, p.9, tradução nossa). Para ele o governo já incluiu o setor privado e a sociedade civil, atuando em vários níveis territoriais de ação, dispensando dessa forma o conceito de governança, normalmente utilizado para se referir a sistemas de formulação de políticas que vão além do Estado (KEATING, 2001). 
Nessa medida, a visão de governo defendida por Keating, corrobora tanto à definição de paradiplomacia defendida por Conargo, que tem como centralidade o envolvimento de um governo não-central nas relações internacionais, quanto à definição de Der Derian, que trata da pluralidade de entidades que podem se envolver com a paradiplomacioa. Além do que, para Keating "A paradiplomacia também se caracteriza por um alto grau de envolvimento da sociedade civil e do setor privado. Isso varia de acordo com fatores políticos e institucionais". (KEATING; ALDECOA; 1999, p. 9, tradução nossa).

Diante disso, outro complemento à definição de paradiplomacia que se pretende defender neste estudo é a visão de Brian Hocking (1993 apud. AGUIRRE, 1999) sobre o assunto. Sua principal contribuição para nossa argumentação diz respeito à relevância do contexto histórico e político de cada local para a constituição de suas práticas paradiplomáticas.

Para o autor, a paradiplomacia é um neologismo dispensável pois representa nada mais que uma dimensão doméstica de um fenômeno tradicional da política internacional (a diplomacia), que vem ocorrendo de forma descentralizada em decorrência dos processos de globalização que torna cada vez mais complexas as relações internacionais (HOCKING, 1993 apud. AGUIRRE, 1999). E é justamente devido a esta visão - de que as relações internacionais, cada vez perpassam mais pelas localidades e não apenas pelo governo central, representante do Estado - que o autor defende que as formas de atuação internacional de cada localidade são heterogêneas entre si, pois estão imbricadas em uma rede de interações multinível, na qual questões domésticas e internacionais se comunicam e variam conforme os contextos em que cada região está inserida. (AGUIRRE, 1999).

\footnotetext{
Os Governos Não-centrais estão localizados em um meio diplomático complexo que não reconhece os territórios exclusivos do doméstico e do internacional, mas combina os dois de várias maneiras a pedido de uma gama de forças localizadas em diferentes níveis políticos. Aqui, a diplomacia internacional não é considerada um processo segmentado presidido por guardiões indiscutíveis, mas como uma teia de interações com um elenco variável de jogadores que irão interagir de maneiras diferentes dependendo da questão, de seus interesses e da capacidade de atuar em um ambiente político multinível. (HOCKING, 1993, p. 36 apud AGUIRRE, 1999, p. 200, tradução nossa).
} 
Para o autor, nesse ambiente complexo da política internacional multinível, a atuação internacional dos governos não-centrais (GNC) não tem que ser analisada a partir de suas relações com os governos centrais, como inicialmente Duchacek (1986 apud. AGUIRRE, 1999) e Soldatos (1990 apud. AGUIRRE, 1999) trataram o tema. Para Hocking (apud. AGUIRRE, 1999) as atividades internacionais dos GNC devem ser estudas a partir de suas próprias posições. "No quadro abrangente da diplomacia 'multicamadas' ou 'catalítica' de Hocking, os GNCs são na verdade 'atores' totalmente internacionais, tão complexos e 'plurais' quanto o 'Estado' a que pertencem." (AGUIRRE, 1999, p. 201, tradução nossa).

Nesses termos, em resumo, a interpretação de paradiplomacia utilizada neste estudo é: a interação de governos não-centrais - compreendidos aqui como o conjunto de entidades que extrapolam as estruturas formais do estado na formulação de políticas públicas, incluindo portanto não apenas o setor público, mas podendo também conter o setor privado, o terceiro setor e sociedade civil - com atores submetidos a jurisdições distintas da sua (provenientes de outro Estado ou economia) com o objetivo de promover questões diversas de forma a mediar realidades distintas convergentes ou não. Dessa forma, damos sequência ao estudo, verificando como a paradiplomacia ocorre nas regiões de fronteira, a fim de verificar seu potencial para o desenvolvimento dessas localidades muitas vezes marginalizadas.

Como viu-se até aqui, as cidades-gêmeas brasileiras, de forma geral, apresentam baixos índices de desenvolvimento em comparação a média nacional. As dificuldades apresentadas no início deste artigo, muitas vezes, são acompanhadas de uma realidade particular às localidades fronteiriças que amplia a quantidade de questões a serem abordadas nessas regiões ao se pensar em desenvolvimento, quando comparadas a outras localidades. Isso inclui, por exemplo, práticas, legais e irregulares, relativas ao trânsito fronteiriço tais como descaminho de mercadorias, contrabando e a migração cotidiana de forma regular ou irregular - de pessoas que cruzam os limites internacionais a trabalho, para acessar sistemas de saúde, fazer compras, etc.

Nesse aspecto, é importante destacar que as conurbações urbanas em regiões de fronteira ocorrem justamente pela existência dos limites internacionais. São as diferenças econômicas, cambiais, e culturais entre os países de fronteira que propiciam as trocas e os trânsitos. Se a região de fronteira fosse uma unidade coesa, as interações seriam, 
provavelmente, menos intensas. Devido a essa intensidade das interações, na maioria das vezes essas localidades são co-dependentes: os trabalhadores de uma cidade, muitas vezes são residentes da cidade vizinha do outro país; o comércio local depende do consumo da população da cidade vizinha; o sistema de saúde de uma cidade atende a população do outro país, etc. Assim, se pensarmos que o associativismo intermunicipal ocorre normalmente entre cidades pequenas no interior dos países, a tendência nessas localidades fronteiriças marginalizadas e co-dependentes é de associar-se para atingir objetivos de forma mais eficiente.

Esse tipo de cooperação, por ser realizada entre cidades de países diferentes (logo com legislações distintas) e em zona de fronteira, é chamada de cooperação

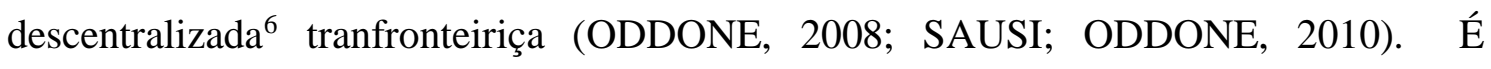
importante comentar esse conceito porque a cooperação e paradiplomacia, apesar de caminharem juntas nesses casos, não são a mesma coisa. O que acontece é que, para que haja cooperação internacional local, é essencial que cada localidade haja de forma paradiplomática, ou seja, buscando se projetar internacionalmente (mesmo que a nível local) a fim de mediar interesses ou conflitos a serem sanados com as demais localidades.

Além disso, a paradiplomacia aparece como ferramenta essencial para o desenvolvimento de políticas comuns nas regiões de fronteira porque, devido a diversos fatores, a institucionalização de processos de cooperação local nem sempre ocorre. Assim, por ser caracteristicamente adaptável, relacional e majoritariamente informal haja vista que não há regulamentação prevista no Direito Internacional Público e não há consenso entre as legislações dos países sobre a atuação internacional das unidades subnacionais (SAUSI; ODDONE, 2010) a paradiplomacia figura como uma opção para superar os obstáculos referentes ao desenvolvimento de regiões fronteiriças que os governos centrais não logram superar.

Como citado no início do artigo, a partir da criação do Mercosul e de seus avanços ao longo da primeira década do século XXI houveram iniciativas que visaram o desenvolvimento e integração das regiões fronteiriças. A esse respeito, Sausi e Oddone

\footnotetext{
${ }^{6} \mathrm{O}$ fato de ser descentralizada remete a atuação direta de entes não-centrais, tais como municípios ou estados. Nesse sentido, cidades que não estão na fronteira podem fazer parte de projetos de cooperação descentralizada. Já quanto a cooperação tranfronteiriça, ela pode ocorrer a partir do governo central, como de instâncias locais. Dessa forma, projetos de cooperação descentralizada e transfronteiriça são exclusividade de localidades subnacionais fronteiriças.
} 
(2010), destacam a criação do Grupo Ad Hoc sobre Integração Fronteiriça (GAHIF) em 2002 e do Grupo de Trabalho de Integração Fronteiriça após 2007. Também, já há mais de três décadas, ocorrem os Comitês de Integração Fronteiriça, que visam aproximações bilaterais entre cidades de fronteira vizinhas dentro do Mercosul (CHIANI, 2019). Além disso, foram institucionalizados pelo Mercosul projetos que visaram fortalecer o protagonismo e a cooperação das cidades e outras unidades subnacionais (estados, províncias e departamentos) tais como o Fórum Consultivo de Municípios, Estados Federados e Províncias e o Mercocidades (ODDONE, 2008). Esses espaços podem ser considerados promotores da paradiplomacia e da interação entre os governos subnacionais dentro do processo de integração regional do Mercosul

Contudo, como os dados apresentados na primeira seção revelam, essas iniciativas não foram capazes de superar as adversidades das regiões fronteiriças. Vários fatores podem ser levantados para justificar isso. Porém, nossa principal hipótese é de que só por meio de interação local, condizente com a realidade de cada localidade será possível o desenvolvimento dessas regiões.

\section{CASOS DE SUCESSO EM COOPERAÇÃO DESCENTRALIZADA TRANSFRONTEIRIÇA POR MEIO DA PARADIPLOMACIA}

Como visto até aqui, além de deslocados do processo de desenvolvimento nacional, as regiões fronteiriças contam com problemáticas transnacionais comuns e nossa argumentação é de que uma alternativa frente a esses problemas é a utilização da paradiplomacia, por parte dos governos não-centrais, como ferramenta de facilitação para a cooperação regional e internacional respondendo às demandas locais. Nesse aspecto, elencamos dois exemplos de utilização da paradiplomacia na superação dos obstáculos de cooperação para o desenvolvimento de regiões transfronteiriças: o caso do Consórcio Intermunicipal de Fronteiras e do Conselho de Desenvolvimento Trinacional.

O Consórcio Intermunicipal de Fronteira - CIF, foi constituído em 2009 pelos municípios brasileiros de Barracão - PR, Bom Jesus do Sul - PR, Dionísio Cerqueira SC e Bernardo de Irigoyen/Missiones na Argentina. O CIF se caracteriza oficialmente como um consórcio público intermunicipal previsto na constituição federal brasileira, tendo, em território brasileiro, personalidade jurídica e documentos normativos 
definidores de sua estrutura (ANDREATTA, 2016). Nessas condições, apenas os municípios brasileiros listados anteriormente constam oficialmente no consórcio a cidade argentina, ainda que participe ativamente das discussões no contexto do CIF, não o integra efetivamente. Isso se dá em função da inexistência de mecanismos legais, tanto no Brasil como na Argentina, que permitam a inclusão de municípios estrangeiros em consórcios nacionais.

Dessa forma, a solução encontrada pela região foi o estabelecimento do consórcio oficialmente em apenas um lado da fronteira, mas com a inclusão paradiplomática da cidade argentina nas agendas do CIF. Nessa localidade, a separação entre os dois países se dá por uma linha imaginária que divide uma rua, que hora é Brasil e logo Argentina. Assim, pensar o desenvolvimento apenas de um lado do limite internacional é praticamente impossível.

Não obstante a incompleta formalização da cooperação internacional, ela tem mostrado bons resultados e pretensos objetivos nas áreas de educação, saúde, desenvolvimento regional, turismo, infraestrutura, entre outras. Um artigo publicado em 2016, intitulado “A contribuição dos consórcios públicos intermunicipais para o desenvolvimento regional transfronteiriço: atuação do Consórcio Intermunicipal da Fronteira" (Henrichs; Silva; Meza, 2016) aponta as principais ações planejadas e executadas pelo CIF até 2013, conforme tabela 1 a seguir. 
Tabela 1: Ações planejadas e executadas pelo CIF.

\begin{tabular}{|c|c|c|}
\hline Ação & Resultado & Situação \\
\hline \multicolumn{3}{|c|}{ Planejamento e desenvolvimento regional } \\
\hline $\begin{array}{l}\text { Lançamento do Programa Lider } \\
\text { (SEBRAE) }\end{array}$ & $\begin{array}{l}\text { Mobilizar, integrar e capacitar lideranças para } \\
\text { elaboração de um plano conjunto para o } \\
\text { desenvolvimento regional. }\end{array}$ & $\begin{array}{c}\text { Realizada } \\
\text { (2009) }\end{array}$ \\
\hline Proposta Caminhos da Fronteira & $\begin{array}{l}\text { Promover o desenvolvimento sustentável } \\
\text { integrado dos municípios da regiāo de } \\
\text { fronteira a partir de quatro eixos estratégicos: } \\
\text { educaçāo, turismo, agroecologia e produtos } \\
\text { locais. }\end{array}$ & $\begin{array}{l}\text { Realizada } \\
\text { (2009) }\end{array}$ \\
\hline EXPOCIF & $\begin{array}{l}\text { Foco na divulgação do comércio, indústria, } \\
\text { turismo, agropecuária, produtos locais, } \\
\text { esportes, lazer e cultura. }\end{array}$ & $\begin{array}{l}\text { Realizada } \\
\text { anualmente }\end{array}$ \\
\hline \multicolumn{3}{|c|}{ Infraestrutura para o desenvolvimento econômico } \\
\hline $\begin{array}{l}\text { Nova aduana integrada de cargas } \\
\text { Brasil/Argentina }\end{array}$ & $\begin{array}{l}\text { Ampliação da capacidade } \\
\text { operacionalização do comércio transnacional. }\end{array}$ & $\begin{array}{c}\text { Realizada } \\
\text { (2014) }\end{array}$ \\
\hline $\begin{array}{l}\text { Definir o traçado da Ferrovia da } \\
\text { Integração Dionisio Cerqueira- } \\
\text { Itajai }\end{array}$ & $\begin{array}{l}\text { Escoamento da produção de bens da regiāo de } \\
\text { fronteira até o porto e vice-versa. }\end{array}$ & $\begin{array}{l}\text { Planejada (em } \\
2015 \text { iniciou a } \\
\text { fase de } \\
\text { elaboração do } \\
\text { projeto) } \\
\end{array}$ \\
\hline $\begin{array}{l}\text { Ferrovia entre Bernardo de } \\
\text { Irigoyen e Posadas }\end{array}$ & $\begin{array}{l}\text { Escoamento de bens da regiāo da fronteira até } \\
\text { a capital da Provincia de Misiones (Arg.). }\end{array}$ & Planejada \\
\hline $\begin{array}{l}\text { Construção da Ruta } 14 \text { entre } \\
\text { Bernardo de Irigoyen a San Pedro }\end{array}$ & $\begin{array}{l}\text { Ligação do centro da Argentina até a fronteira, } \\
\text { facilitando o transporte de cargas pelo Porto } \\
\text { Seco. }\end{array}$ & $\begin{array}{l}\text { Em execução } \\
\text { (início 2010) }\end{array}$ \\
\hline $\begin{array}{l}\text { Instrumentalização do aeroporto } \\
\text { de Dionísio Cerqueira }\end{array}$ & $\begin{array}{l}\text { Operacionalizar voos comerciais e de cargas } \\
\text { no aeroporto de Dionisio Cerqueira. }\end{array}$ & Planejada \\
\hline \multicolumn{3}{|c|}{ Turismo } \\
\hline \multicolumn{3}{|c|}{ Urbanismo e meio ambiente } \\
\hline Projeto de urbanismo integrado & $\begin{array}{l}\text { Melhoramento das vias públicas e } \\
\text { identificação transfronteiriça padronizada. }\end{array}$ & $\begin{array}{c}\text { Malha } \\
\text { asfáltica } \\
\text { executada em } \\
2012 . \\
\text { Iluminação e } \\
\text { calçadas } \\
\text { planejamento } \\
\text { para } 2016 \\
\end{array}$ \\
\hline $\begin{array}{l}\text { Coleta seletiva e reciclagem do } \\
\text { lixo }\end{array}$ & Redução de custos e preservação ambiental. & $\begin{array}{l}\text { Em execução } \\
\text { (desde 2011, } \\
\text { ação contínua) }\end{array}$ \\
\hline \multicolumn{3}{|c|}{ Habitação } \\
\hline $\begin{array}{l}\text { Zerar o déficit habitacional na } \\
\text { fronteira. }\end{array}$ & Construçāo de 930 populares & Planejada \\
\hline Custeio de atendimento hospitalar & Governo Federal e Estadual. & \\
\hline \multicolumn{3}{|c|}{ Educação } \\
\hline $\begin{array}{l}\text { Implantação do Instituto Federal } \\
\text { do Paraná (IFPR) }\end{array}$ & $\begin{array}{l}\text { Oferta de ensino superior e profissionalizante } \\
\text { gratuito e de qualidade. }\end{array}$ & $\begin{array}{c}\text { Realizada } \\
(2015)\end{array}$ \\
\hline Escola bilíngue & $\begin{array}{l}\text { Formação de cidadãos biligues e interativos } \\
\text { social e culturalmente. }\end{array}$ & $\begin{array}{c}\text { Realizada } \\
(2009)\end{array}$ \\
\hline
\end{tabular}

Fonte (HENRICHS; SILVA; MEZA, 2016, p. 20-21).

Como se pode observar, os dados da tabela revelam execução de projetos nas áreas de educação, incluindo uma escola bilingue; saúde, incluindo atendimento hospitalar integrado Paraná/ Santa Catarina/Misiones, promoção da integração regional por meio de feiras dos produtores rurais, dentre outros. Além dos itens descritos nessa tabela, outro estudo sobre o CIF também de 2016 relata a execução do fortalecimento da associação e da cantina de vitivinicultores, bem como da Fábrica do Produtor de Bom Jesus do Sul, indicando o comprometimento do CIF com a questão de emprego e renda da região (ANDREATTA, 2016).

Além do CIF, outro exemplo de utilização da paradiplomacia a favor da cooperação transfronteiriça é o Conselho de Desenvolvimento Trinacional. Composto por entidades privadas e da sociedade civil das cidades de Foz do Iguaçu (BR), Puerto Iguazu 
(AR) e Ciudad del Este (PY), o CODETRI, como é conhecido, foi proposto em 2018 no marco do plano de "Avaliação de Vulnerabilidade e estratégias de adaptação na região trinacional" relativo a construção de resiliência climática a partir da cooperação triangular entre as cidades.

Apesar desse marco oficial, de acordo com Linda Tayen ${ }^{7}$, o processo de formação da rede que compõe o atual CODETRI é anterior e teve início a partir de uma ação estimulada pelo SEBRAE, chamada Fronteiras Cooperativas, que visou a aproximação de tomadores de decisão de cidades fronteiras em diversas localidades brasileiras. Contudo, é de fato apenas em 2018 que o CODETRI é proposto, a partir dos Conselhos Municipais de Desenvolvimento das três cidades (CODEFOZ, CODESPI e CODELESTE).

Os Conselhos de Desenvolvimento municipais são conselhos deliberativos, consultivos e de assessoramento que foram implementados entre 2012 e 2015 pelos respectivos municípios da fronteira conforme legislação municipal de cada cidade. $\mathrm{O}$ primeiro deles foi o de Foz do Iguaçu, que por meio da paradiplomacia influenciou a criação dos outros dois conselhos no mesmo modelo. Assim, em 2018, a criação do CODETRI foi pensada a partir da confluência dos três conselhos com a ideia inicial de se criar "[...]Câmaras Trinacionais, onde poderiam ser elaborados planejamentos integrados entre as cidades" (SAKAI; et.al. 2018).

$\mathrm{Na}$ ocasião, o CODETRI foi proposto com as mesmas características dos demais conselhos, sendo consultivo e deliberativo. Porém, como ainda não foi institucionalizado, o que é deliberado em Assembleia Trinacional, passa posteriormente pelos Conselhos Municipais.

Exemplo de ação propostas pelo CODETRI é o projeto “\#AquiCuidamos” voltado para a educação ambiental integrada sobre resíduos sólidos na região trinacional. Além dele, outras frentes de atuação do Conselho até o momento foram reivindicação de representação no Parlasul; a criação de câmaras técnicas de Turismo e Logística, além da já existente câmara de Meio Ambiente; e a participação em projetos como o Concurso de Experiências Iguassu - realizado em parceria com o projeto Innovact, financiado pela União Europeia. (CIDADES, 2019).

\footnotetext{
${ }^{7}$ Informação verbal proferida em apresentação realizada no dia 30/09/2020 durante encontro do grupo "Novos Arranjos de Pesquisa e Inovação Trinacioanal" (NAPI).
} 
Observando os dois casos apresentados, verifica-se que apesar de ambos fazerem uso da paradiplomacia em seus processos de cooperação e ambos obterem êxitos nesse trâmite há uma divergência crucial que corrobora com o argumento de a paradiplomacia ser um estilo de mediação muito adaptável. No caso do CIF, os principais atores envolvidos são as prefeituras das cidades que se organizaram em torno de uma entidade institucionalizada e de forma paradiplomática agregaram o município argentino. Porém no caso do CODETRI, os atores da cooperação são os Conselhos de Desenvolvimento, compostos pela socidade civil (majoritariamente entidades privadas e do terceiro setor) organizados em uma entidade não institucionalizada, porém ainda assim deliberativa e operante por sua ordinariedade e intenção.

\section{CONSIDERAÇÕES FINAIS}

Ao longo do estudo visamos apresentar o cenário de baixo desenvolvimento no qual se inserem as cidades-gêmeas de fronteira brasileiras e debater a paradiplomacia como uma ferramenta viável para a promoção de cooperação transfronteiriça visando o desenvolvimento dessas regiões marginalizadas. Na primeira seção evidenciamos os baixos índices de desenvolvimento dessas localidades em comparação à média nacional e pudemos identificar déficits nas áreas de saneamento básico (esgotamento); escolarização; mortalidade infantil e rendimento mensal. Os dados corroboram à contextualização inicial de marginalidade dessas regiões.

Dessa forma, na segunda seção realizamos o debate conceitual sobre paradiplomacia, pretendendo levantar pontos de convergência entre essa, relativamente, recente prática internacional e a possibilidade de utilizá-la como ferramenta de promoção do desenvolvimento cooperativo em regiões transfronteiriças. Aqui defendemos que a noção de governo sub-nacional deve ser entendida de forma ampla, abrangendo não apenas as estruturas formais do Estado representadas pelos poderes públicos municipais, mas também a sociedade civil. Além disso, identificamos a paradiplomacia como uma atitude de projeção internacional de interesses públicos desses atores sub-nacionais visando a mediação de interesses com outros atores, e localizamos essa prática como um mecanismo facilitador da cooperação internacional. 
Por fim, trouxemos dois casos de cooperação transfronteiriça com resultados de desenvolvimento regional transfronteiriço que ocorreram com base na paradiplomacia. De forma a aprofundar a comparação entre os dados apresentados na primeira seção e na última, pode-se dizer que faltam dados quantitativos que nos permitam verificar a efetividade, ou não, da atuação paradiplomática na superação dos obstáculos apresentados. Contudo, as avaliações qualitativas dos casos elencados ao final do estudo apontam para o sucesso na implementação de mudanças em regiões que apostaram na paradiplomacia nas mesmas esferas apresentadas como déficit na primeira parte.

A questão do saneamento básico e meio ambiente tem sido pauta de implementação do projeto "\#Aquicuidamos", e na verdade funcionou como impulso de formação do CODETRI. Com relação à escolarização, o CIF é exemplo de cooperação regional transfronteiriça pela implementação da escola de fronteira bilíngue, assim como na movimentação para instalação de um campus do IFPR, concretizado em 2015. E quanto a questão de renda o CIF também se apresenta com boas práticas ao promover o fortalecimento de cooperativas de produtores locais.

Deste modo, evidenciamos como a paradiplomacia pode ser estratégia importante para promover o desenvolvimento sustentável de cidades fronteiriças indepentemete de institucionalização formal desses processos.

\section{REFERENCIAS BIBLIOGRÁFICAS}

AGUIRRE, I. Making sense of paradiplomacy? An intertextual enquiry about a concept in search of a definition. Regional \& Federal Studies. Londres, v. 9, n. 1, p. 158-208. fev. 1999.

ALDECOA, F.; KEATING, M. (Ed.). Paradiplomacy in action: the foreign relations of subnational governments. Nova Yorke: Taylor \& Francis, 1999.

BRASIL. Comissão Permanente para o Desenvolvimento e a Integração da Faixa de Fronteira. Ministério da Integração Nacional (org.). Relatório II Encontro Anual de Núcleos Regionais de Fronteira. Tabatinga: Diálogos Setoriais, 2012. 117 p. Disponível em:

$<$ http://www.sectordialogues.org/sites/default/files/acoes/documentos/dpir0001_perita _local_-_produto_final.pdf>. Acesso em: 02 de out. de 2020.

CARNEIRO FILHO, C. P.; CAMARA, L. B. Políticas públicas na faixa de fronteira do Brasil: PDFF, CDIF e as políticas de segurança e defesa. Confins [Online], 41, 2019, posto online no dia 17 setembro 2019. Disponível em: 
<http://journals.openedition.org/confins/22262>. DOI: 10.4000/confins.22262. Acceso em: 30 de set. de 2020.

CHIANI, A. M. ¿Qué rol cumplen los Comités de Integración en el proceso de integración regional? In: XVII CONGRESSO INTERNACIONAL DO FOMERCO, 17., 2019, Foz do Iguaçu. Anais eletrônicos. Foz do Iguaçu: Fórum Universitário Mercosul, 2019. p. 111 .

Disponível

em: https://www.congresso2019.fomerco.com.br/resources/anais/9/fomerco2019/156876652 9_ARQUIVO_e16babe4d0a34bd9a9f357bb001401bb.pdf. Acesso em: 07 de out. de 2020 .

CIDADES das três fronteiras poderão ter projeto integrado de educação ambiental sobre residuos sólidos. CODEFOZ, Foz do Iguaçu, 11 nov. 2019. Disponível em: $<$ http://www.codefoz.org.br/2019/11/cidades-das-tres-fronteiras-poderao-ter-projetointegrado-de-educacao-ambiental-sobre-residuos-solidos/> Acesso em: 08 de out. de 2020 .

CONARGO, N. Diplomacy and paradiplomacy in the redefinition of international security: dimensions of conflict and cooperation. Regional \& Federal Studies. Londres, v. 9, n. 1, p. 40-57. fev. 1999.

DORFMAN, A. A cultura do contrabando e a fronteira com um lugar de memória. Estudios Historicos, n. ${ }^{\circ}$ 01, 2009.

HENRICHS, J.; SILVA, C.; MEZA, M. L. A contribuição dos consórcios públicos intermunicipais para o desenvolvimento regional transfronteiriço: atuação do Consórcio Intermunicipal da Fronteira. In: Informe Gepec, Toledo, v. 20, n. 1, p. 8-25, jan./jun. 2016.

KEATING, M. Governing cities and regions: territorial restructuring in a global age. In: SCOTT; A. J. (ed.), Global City-Regions: Trends, Theory, Policy. Oxford: Oxford University Press, 2001, p. 371-390.

MARTINS, José de Souza. Fronteira: A Degradação do Outro nos Confins do Humano. São Paulo: Contexto, 2009.

ODDONE, C. N. La Red de Mercociudades: Globalización, integración regional y desarrollo local. Ugarit, 2008.

SAKAI, P.; SAKAI, M.; SCHNEIDER, T.; OBERLING, D. F.; OREGGIONI, F.; LÓPEZ, L.; FRANZINI, A. C.; AQUINO, C.; TISCHNER, A.; CABALLERO, N.; PENAGOS, J. Vulnerability Assessment and Adaptation Strategies of the TriangleCity Region. Foz do Iguaçu: The Climate Resilient Cities in Latin America initiative, Cliamate and Development Knowledge Network (CDKN) and Canada's International Development Research Centre (IDRC), 2017, 238 p. 
SAUSI, J L; ODDONE, N. Cooperación e integración transfronteriza en el Mercosur: el caso de la triple frontera argentina-brasil-paraguay. In: GARCIA, J M; PACHECO, A V (org.). Governanza y Prevención Transversal en la Frontera Norte de México. Cidade do México: Marisa Pacheco López, 2013. p. 157-204. Disponível em: $<$ https://www.casede.org/BibliotecaCasede/GOBERNANZA_PREVENCION_TRANS VERSAL_FRONTERANORTE_MEXICO.pdf\#page=158>. Acesso em: 30 de set. de 2020. 